\title{
O reconhecimento judicial de uniões estáveis paralelas: a família como garantia institucional na jurisprudência do Supremo Tribunal Federal ${ }^{*}$
}

\author{
The judicial recognition of paralell stable \\ unions: the family as an institutional guarantee \\ in the brazilian Supreme Court Jurisprudence
}

Marcel Fortes de Oliveira Portela ${ }^{1}$

Recebido em: 25/08/2015.

Aprovado em: 31/08/2015.

Bacharel em Direito pela Faculdade de Direito da Universidade de Brasília (FD/UnB). Especialista em Direito Penal e Controle Social pelo Centro Universitário de Brasília (UniCEUB).

\begin{abstract}
Resumo
A jurisprudência do Supremo Tribunal Federal firmou a impossibilidade de reconhecimento de uniões estáveis concomitantes ou paralelas, reduzindo a união estável que foi constituída em segundo lugar ao status de concubinato. A referida postura pressupõe a concepção do casamento monogâmico como forma suprema de manifestação da garantia institucional da família. Essa conclusão torna imprescindível o enfrentamento da questão das garantias institucionais em qualquer discussão séria sobre o tema das famílias paralelas, uma vez que a monogamia é concebida como componente do núcleo essencial de qualquer entidade familiar. Observa-se tendência de atualização do conteúdo material da garantia institucional da família, para ampliar a proteção constitucional às mais diversas formas de estruturação do afeto. Ao final, conclui-se que marco teórico liberal e radicalmente antidogmático, que partisse de uma perspectiva não monolítica da família, fundada na mais ampla liberdade afetiva, acompanhada de seu correlato a responsabilidade integral pelas uniões afetivas constituídas, dispensaria o instrumental das garantias institucionais, por outro lado permitindo a proteção de todas as modalidades de família pela importância que essas formações assumem na vida das pessoas, sem que a sua garantia sirva para hipostasiar valores hegemônicos de uma forma de vida tradicional. Tal abordagem poderia permitir o reconhecimento de eficácia jurídica ao paralelismo afetivo.
\end{abstract}

Palavras-chave: Paralelismo Afetivo. Garantias Institucionais. Casamento. Monogamia. Uniões Estáveis Simultâneas.

\begin{abstract}
The Supreme Court jurisprudence has forbidden the recognition of concurrent or parallel partnerships/stable unions, reducing the stable union/partnership that was constituted in second place to the status of concubinage. That posture presupposes the concept of monogamous marriage as the supreme form of the manifestation of the institutional guarantee of the family. This conclusion makes it imperative to address the issue of institutional guarantees in any serious discussion on the subject of parallel families, since monogamy is defined as a component of the essential core of any family unit. There has been a tendency to update the substantive content of the institutional guarantee of family to extend constitutional protection to the most diverse forms of family structures. A liberal and radically anti-dogmatic theoretical framework, which paves the way to a non monolithic perspective of the family, founded on broader affective freedom, accompanied by its correlate, the full responsibility for the established affective unions/partnerships, can dispose of the instrument of the institutional guarantees, and its consequence of hypostatizing hegemonic values of a traditional way of life, at the same time, enabling the protection of all family forms for their importance in people's lives. Such an approach could allow the recognition of legal effect to the affective parallelism.
\end{abstract}

Keywords: Affective Parallelism. Institutional Guarantees. Marriage. Monogamy. Parallel partnerships/stable unions. 


\section{Introdução: as uniões de fato e o concubinato}

Há não muito tempo, dizia-se que a família, instituição medular da sociedade, era constituída pelo casamento civil (Art. 175, caput, da Emenda Constitucional $n^{\circ} 1$ de 1969). Uniões de fato entre um homem e uma mulher não recebiam o reconhecimento das autoridades do Estado, como entidades familiares, sendo-lhes atribuído o status de concubinato - do latim "cum cubare", dormir junto - sendo os filhos nascidos dessa relação tidos como ilegítimos, porque não concebidos sob o pálio do matrimônio.

Entendia-se que o que diferenciava as uniões de fato do casamento era exatamente a "liberdade que os componentes das primeiras tinham para descumprir os deveres do último". Dizia-se que "elas poderiam ser terminadas a qualquer instante", independentemente de quanto tempo houvesse durado, "sem que ao companheiro abandonado coubesse qualquer reparação" ${ }^{2}$. Com a finalidade de evitar esse tipo de injustiça, o STF editou o enunciado 380 de suas Súmulas, ainda vigente, mas aplicado em contexto diferente daquele em que foi formulado, segundo o qual: "comprovada a existência da sociedade de fato entre os concubinos, é cabível a sua dissolução judicial, com a partilha do patrimônio adquirido pelo esforço comum".

A companheira ou o companheiro de uma união de fato não se considerava como integrante de entidade familiar, o que seria ofensa ao casamento, por este já ter sido constituído anteriormente ou porque sua forma simplesmente não foi empregada, e isso não se poderia admitir. No máximo, o companheiro que se sentisse abandonado poderia lutar, em outra ação judicial, a ser impetrada na Vara Cível, nunca na de Família, pelo reconhecimento de uma parceria ou de uma sociedade de fato, como se o que o tivesse aproximado da pessoa com a qual convivera fosse o objetivo de obter lucros ou a conveniência econômica. E, para que demonstrasse o referido esforço comum na constituição de patrimônio conjunto, teria que acumular amplo acervo probatório.

A Constituição de 1988 veio reestruturar e reorganizar essa e muitas outras matérias. Incorporou, como já não era sem tempo, profundas transformações na estruturação das famílias, consolidando e acelerando o processo de mudanças sociais nessa área. Em primeiro lugar, rompendo com a tradição de todas as constituições anteriores, deixou de reconhecer o casamento como célula essencial da família, como a forma taxativa de organização do afeto, falando, no caput do Art. 226, que a família, sem maiores qualificações, será objeto de proteção especial do Estado, dá ensejo à configuração do pluralismo familiar, com a mais ampla liberdade de escolha de modos de convivência, típica da disciplina das relações privadas. O Estado não diz mais aos cidadãos como direcionar seu afeto ${ }^{3}$.

O casamento não desaparece, entretanto, e permanece como entidade familiar explicitamente reconhecida pela Constituição. A diferença, dessa vez, é que, ao lado dele, emergem a família monoparental (Art. 226, $\$ 4^{\circ}$ ) e a união estável (Art. 226, $\$ 3^{\circ}$ ), como entidades familiares expressamente contempladas pelo texto da Carta Magna. Esse elenco não exclui, como já referido, ainda outras uniões ou agrupamentos familiares, uma vez que, extinto o monopólio do matrimônio, o vetor imperante é o do direito de amar livremente.

A união estável veio substituir a preconceituosa e discriminatória expressão do concubinato e, finalmente, alçar as uniões de fato ao status de família que mereciam. Aos filhos dessas uniões, como a todos os filhos, foram assegurados os mesmos direitos, tendo sido vedadas denominações pejorativas (Art. 227, \$ $6^{\circ}$ ). Parecia ser o fim do concubinato.

No entanto, o monismo do casamento fincou raízes na cultura jurídica nacional e no entendimento dos tribunais, fazendo com que legisladores e juízes, mesmo sob a égide da nova Constituição e no contexto de um paradigma de interpretação constitucional renovado, continuassem a insistir na postura tutelar e paternalista que mantinham anteriormente, impondo, de cima para baixo, a forma do casamento e pressupondo, ao arrepio da nova ordem, a precedência dessa forma de organização do afeto sobre todas as outras. É assim que o requisito da finalidade de constituir família, previsto pela legislação civil (Lei $n^{\circ} 9.278$ de 1996 e o Código Civil vigente), para a configuração da
3 LÔBO, Paulo Luís Neto. Famílias. São Paulo: Saraiva, 2010. p. 23. 
união estável, continuou a ser confundido com a união more uxorio, ou seja, à maneira do casamento ou com aparência de casamento. Também a affectio maritalis, tradicionalmente relacionada com o casamento, foi incluída dentre os requisitos da união estável.

De fato, para a configuração da união estável, no regime atual, faz-se necessário o preenchimento de requisitos objetivos e subjetivos. Podem ser apontados, como de ordem subjetiva: a convivência more uxorio e a affectio maritalis. A primeira é entendida como "comunhão espiritual e material, envolvendo assistência mútua, atenção recíproca, afeto e associação de interesses típicos da vida em conjunto, em semelhança à situação de pessoas casadas". A segunda se confunde com o "ânimo ou o objetivo de constituir família”, propriamente dito, sendo um aspecto anímico de difícil delimitação. Normalmente, é identificada por meio dos sinais da convivência à moda conjugal, ou seja, dissolve-se no requisito anterior. Como já referido, esse requisito serve para impedir que meros encontros amorosos ou namoros configurem a entidade familiar, mas as situações concretas estão sempre a desafiar os modelos jurídicos ${ }^{4}$.

Para a doutrina majoritária, os sinais dessa convivência que costumam ser apontados são os seguintes: “a mantença de um lar comum, frequência conjunta a eventos familiares e sociais, eventual casamento religioso [sem efeitos civis], existência de filhos havidos dessa união, mútua dependência econômica, empreendimentos em parceria, contas bancárias conjuntas etc." 5 .

E, como de ordem objetiva, elencam-se os seguintes requisitos: “a) a diversidade de sexos; b) notoriedade; c) estabilidade ou duração prolongada; d) continuidade; e) inexistência de impedimentos matrimoniais; e f) relação monogâmica" (cf. Art. 1723 do CC) ${ }^{6}$

Hoje a exigência de diversidade sexual para a configuração da união estável foi superada após muita divergência jurisprudencial, quando do julgamento da

GONÇALVES, Carlos Roberto. Direito civil brasileiro. 6. ed. São Paulo: Saraiva, 2009. v. 6. p. 556.

5 OLIVEIRA, Euclides Benedito de. União estável: do concubinato ao casamento. 6. ed. São Paulo: Método, 2003. p. 133.

6 GONÇALVES, Carlos Roberto. Direito civil brasileiro. 6. ed. São Paulo: Saraiva, 2009. v. 6. p. 557.
ADPF $n^{\circ} 132-R J$, que foi recebida parcialmente como ADI no 4277-DF, tendo sido fixado o entendimento pelo STF de que interpretação conforme a Constituição do referido Art. 1723 do Código Civil não poderia excluir as uniões homoafetivas da proteção especial devida pelo Estado a essa tipologia familiar.

No entanto, a preferência dada pelo Direito à forma do casamento não se evidencia somente quando se impõe como requisito subjetivo para materialização da união estável a convivência dos companheiros como se fossem marido e mulher, mas também quando se requer dos companheiros em potencial a ausência de impedimentos matrimoniais e a observância da monogamia.

Nesse sentido o novo Código Civil, que já nascia ultrapassado em vários aspectos, "ressuscita" a figura do concubinato e dispõe, com a finalidade expressa de afastar as uniões simultâneas ou paralelas do regime da união estável, que: “Art. 1.727. As relações não eventuais entre o homem e a mulher, impedidos de casar, constituem concubinato". Assim, hoje, como dantes, as uniões constituídas ao lado de um casamento, cuja sociedade conjugal não tenha sido dissolvida pela separação judicial ou de fato (Art. 1723, $₫ 1^{\circ}$ ), ou cujo vínculo não tenha sido rompido pelo divórcio, não são consideradas entidades familiares, mesmo que preencham todos os outros requisitos de uma união estável, sendo remetidas à solução obrigacional pré-constitucional.

\section{Análise do precedente paradigmático do Supremo Tribunal Federal - Recurso Ex- traordinário n³ 3.977.628-BA}

O Supremo Tribunal Federal já teve oportunidade de se posicionar sobre a questão das uniões simultâneas sob a nova ordem constitucional. No julgamento do Recurso Extraordinário no 3.977.628-BA, relatado pelo Ministro Marco Aurélio de Melo, concluído no dia 03/06/2008, mas cujo julgamento começou ainda em 2005, não tendo, portanto, ao recurso sido atribuída repercussão geral (nos termos da Lei $\left.\mathrm{n}^{\circ} 11.418 / 2006\right)$, o entendimento firmado pela maioria foi o da absoluta distinção entre união estável e concubinato, especialmente pelo caráter ilícito dessa 
última forma de convivência. Veja-se a ementa:

Supremo Tribunal Federal

Recurso Extraordinário 3977628 - BA

Relator: Min. Marco Aurélio de Mello

Ementa: COMPANHEIRA E CONCUBINA - DISTINÇÃO. Sendo o direito uma verdadeira ciência, impossível é confundir institutos, expressões e vocábulos, sob pena de prevalecer a babel. UNIÃO ESTÁVEL PROTEÇÃO DO ESTADO. A proteção do Estado à União Estável alcança apenas as situações legítimas e nestas não está incluído o concubinato. PENSÃO - SERVIDOR PÚBLICO - MULHER - CONCUBINA - DIREITO. A titularidade da pensão decorrente do falecimento de servidor público pressupõe vínculo agasalhado pelo ordenamento jurídico, mostrando-se impróprio o implemento de divisão a beneficiar, em detrimento da família, a concubina ${ }^{7}$.

Em relação à ementa, é possível fazermos leitura bastante pejorativa da união simultânea, como modalidade de concubinato, na medida em que é entendida como situação ilegítima, repudiada pelo ordenamento jurídico, em face da qual a família verdadeira deve ser protegida.

A previsão do Art. 1727 não traz a disciplina desse modo de convivência denominado de concubinato, exatamente porque a intenção do legislador buscou excluí-lo de qualquer disciplina. Dizer que concubinato é diferente de união estável não basta para afastar o reconhecimento daquele como uma forma de estruturação das relações de afeto. É preciso mais do que uma distinção, a linha de raciocínio pressupõe hierarquia. A hierarquia, por sua vez, subentende uma ordem valorativa, segundo a qual o concubinato adulterino deveria ser execrado, porque representaria desvirtuamento da norma familiar e violação dos deveres dos companheiros. Configuraria, em suma, união espúria, imoral e, por consequência, ilícita.

Mas essa hierarquia não encontra seu vértice nas uniões de fato legítimas, não adulterinas. Em realidade, ela vai terminar na forma suprema de constituição de família, ou seja, o casamento civil. Em

BRASIL. Supremo Tribunal Federal. Recurso Extraordinário. RE 397762 BA. Primeira Turma. Recorrente: Estado da Bahia. Recorrido: Joana da Paixão Luz. Relator: Min. Marco Aurélio. Brasília, 03 de junho de 2008. Disponível em: <http://stf.jusbrasil.com.br/jurisprudencia/2918741/ recurso-extraordinario-re-397762-ba $>$. Acesso em: 17 set. 2015. relação à norma constitucional do Art. 226, $\$ 3^{\circ}$ da $\mathrm{CF}$, que, em sua parte final, prevê que a lei deverá facilitar a conversão da união estável em casamento, o intérprete da Suprema Corte extraiu não somente uma faculdade, mas um mandamento e um programa. Essa interpretação está calcada na concepção da oficialidade da união matrimonial. A supremacia do casamento além de tudo imporia um modelo a ser observado pelas outras famílias, inclusive pelas uniões de fato, o que leva à extensão dos requisitos e dos deveres de uma modalidade familiar à outra. $\mathrm{O}$ dever de fidelidade (Art. 1566, I do CC), nessa perspectiva, entendido como monogamia e exclusividade sexual, típico da união conjugal, é estendido à união estável como dever de lealdade (Art. 1724 do CC). E o dever de fidelidade é compreendido como requisito para a configuração de ambas as formas familiares.

Ora, um dever não constitui requisito de constituição de família. Os deveres podem ser violados e a família ainda existir como centro de estruturação do afeto, embora o descumprimento dos deveres fundamentais de auxílio mútuo, de atenção recíproca e de cuidados com os filhos possa influir na organização da família e possa levar à sua dissolução.

Mas esse não constitui o maior problema dessa linha de raciocínio. O mais grave é que, com a preferência concedida ao casamento e com a imposição do dever de fidelidade e lealdade, diversas uniões, de fato, que apresentam todos os requisitos típicos de entidades familiares (estabilidade, publicidade, durabilidade, afetividade) são deliberadamente atiradas à margem do direito, não recebendo proteção e todo o desprezo dos órgãos estatais.

É nesse sentido que o voto do Ministro relator, no caso referido, fixa que:

[...] todavia, a união estável protegida pela Constituição pressupõe prática harmônica com o ordenamento em vigor. Tanto é assim que, no artigo 226 da Carta da República, tem-se como objetivo maior a proteção do casamento. [...] O reconhecimento da união estável pressupõe possibilidade de conversão em casamento. O reconhecimento da união estável entre o homem e a mulher como entidade familiar, devendo a lei facilitar a sua conversão em casamento, direciona à inexistência de obstáculo a este último ${ }^{8}$

8 BRASIL. Supremo Tribunal Federal. Recurso Extraordi- 
$\mathrm{Na}$ mesma toada, vai a argumentação do $\mathrm{Mi}$ nistro Ricardo Lewandowski, que acompanhou o relator:

[...] a estabilidade só pode ser considerada se houver a possibilidade de, nos termos da Constituição e da legislação infraconstitucional com ela coerente, transformar-se [a união estável] em casamento [...].

Quer-me parecer que, de uma leitura estrita deste $₫ 3^{\circ}$, temos de entender que esta união estável, esta entidade familiar referida neste dispositivo constitucional é uma espécie de embrião do futuro casamento. ${ }^{9}$

O raciocínio ainda não está completo, no entanto. Falta o elemento valorativo. Se o casamento constitui a norma da família, a sua forma superior, isso ocorre porque este viabiliza a afirmação de certos valores que não são devidamente contemplados pela absoluta liberdade de constituição familiar. O principal deles, como já referido, é a monogamia. O império da monogamia é tão abrangente que qualquer união que a desrespeite é considerada, por presunção absoluta, instável, precária e conflituosa. Mais ainda, é inadequada, inviável, imoral, desnaturada.

É nesse sentido que, em seu voto, a Ministra Carmen Lúcia enuncia:

[...] em primeiro lugar, tenho para mim que o $\$ 3^{\circ}$ do artigo 226 , ao se referir à união estável, abarca única e exclusivamente, aquela união que pode ser considerada dotada de tal equilíbrio que a presença de outro núcleo nesse sentido de casamento a instabilizaria. $[\ldots]$

[Debatendo com o Ministro Ayres Britto] Mas não há como estabilizar algo que é plural. [...] Não, Ministro, é que a segunda união "incestabiliza" a primeira; uma segunda união "incestabiliza" a primeira ${ }^{10}$.

nário. RE 397762 BA. Primeira Turma. Recorrente: Estado da Bahia. Recorrido: Joana da Paixão Luz. Relator: Min. Marco Aurélio. Brasília, 03 de junho de 2008. Disponível em: <http://stf.jusbrasil.com.br/jurisprudencia/2918741/ recurso-extraordinario-re-397762-ba>. Acesso em: 17 set. 2015.

9 BRASIL. Supremo Tribunal Federal. Recurso Extraordinário. RE 397762 BA. Primeira Turma. Recorrente: Estado da Bahia. Recorrido: Joana da Paixão Luz. Relator: Min. Marco Aurélio. Brasília, 03 de junho de 2008. Disponível em: <http://stf.jusbrasil.com.br/jurisprudencia/2918741/ recurso-extraordinario-re-397762-ba $>$. Acesso em: 17 set. 2015.

10 BRASIL. Supremo Tribunal Federal. Recurso Extraordinário. RE 397762 BA. Primeira Turma. Recorrente: Estado da Bahia. Recorrido: Joana da Paixão Luz. Relator: Min. Marco Aurélio. Brasília, 03 de junho de 2008. Disponível
Também é essa a manifestação do Ministro Carlos Alberto Menezes Direito em seu voto:

[...] é só que a preocupação que existe, pelo menos na minha perspectiva [...] é que a interpretação do $\$ 3^{\circ}$ do artigo 226 , se não forem levados em consideração esses balizamentos legais com relação à existência do matrimônio, nós poderíamos abrir ensanchas a uma multiplicidade de reconhecimento de uniões que não seriam absolutamente estáveis porque seriam múltiplas.

[...] esse raciocínio pode levar uma pessoa a manter dez relações ao mesmo tempo, com a fragmentação da situação jurídica relativa à união estável. ${ }^{11}$

Observe-se que a presunção dos julgadores é de que a simultaneidade de relacionamentos afastaria, automaticamente, a estabilidade, como requisito da configuração de uma estrutura familiar. Mas isso, antes de tudo, como é possível extrair dos próprios votos, constitui juízo normativo e não juízo de fato. Não é uma afirmação que pode ser contraditada por exemplos concretos em contrário. "Logo juízo de valor não autorizado pela realidade, mas imposto a ela" ${ }^{12}$.

No mesmo caso em questão, os ministros se recusaram a ver como estável uma união paralela ao casamento que durara 30 anos e chegou a gerar sete filhos. Essa recusa de enxergar essas uniões como família e de garantir-lhes a proteção do Estado é eticamente fundada, é uma decisão valorativa, mas os votos fazem parecer que ela resulta da experiência comum e da observação dos fatos. Mesmo assim, a intervenção do Estado na vida privada, não para assegurar direitos, mas para restringir liberdades, sob esse pretexto, é absolutamente perniciosa, adquirindo

em: <http://stf.jusbrasil.com.br/jurisprudencia/2918741/ recurso-extraordinario-re-397762-ba>. Acesso em: 17 set. 2015.

11 BRASIL. Supremo Tribunal Federal. Recurso Extraordinário. RE 397762 BA. Primeira Turma. Recorrente: Estado da Bahia. Recorrido: Joana da Paixão Luz. Relator: Min. Marco Aurélio. Brasília, 03 de junho de 2008. Disponível em: <http://stf.jusbrasil.com.br/jurisprudencia/2918741/ recurso-extraordinario-re-397762-ba>. Acesso em: 17 set. 2015.

12 BRASIL. Supremo Tribunal Federal. Arguição de Descumprimento de Preceito Fundamental. ADPF 132 - RJ. Tribunal Pleno. Arguente: Governo do Estado do Rio de Janeiro. Arguidos: Governador do Estado do Rio de Janeiro, Assembleia Legislativa do Estado do Rio de Janeiro e Tribunais de Justiça dos Estados. Relator: Min. Ayres Britto. Brasília, 05 de maio de 2011. Disponível em: <http:// redir.stf.jus.br/paginadorpub/paginador.jsp?docTP=AC\&docID $=628633>$. Acesso em: 17 set. 2015 . 
aspecto paternalista, desconforme ao Estado Democrático de Direito.

\section{As garantias institucionais}

A Constituição, todavia, nada nos fala sobre a disciplina da união estável ou do casamento, como pouco nos fala sobre a disciplina da propriedade e da herança. Como já referido, é a legislação infraconstitucional que determina o detalhamento e as especificidades do seu regramento, bem como as suas inter-relações. Não obstante, esses institutos são expressamente assegurados pelo texto constitucional. Seriam apenas instrumentos de conformação de direitos subjetivos ou estariam previstos como objetos de proteção diferenciada, adquirindo específica relevância normativa?

A interpretação da teoria liberal clássica dos direitos fundamentais, como direitos individuais, realizáveis na relação entre Cidadão e Estado, cujo objetivo precípuo seria proteger os sujeitos particulares contra as intervenções de caráter imperativo do Poder Público, como regra, consideradas ilegítimas, uma vez que restringiriam a liberdade geral originária das pessoas, exigindo, portanto, um fundamento legal para justificá-las e, nesse sentido, a sanção popular, viveu o seu apogeu e a sua derrocada na curta, mas bastante representativa experiência da República de Weimar.

Essa concepção de uma liberdade pré-estatal originária, que somente poderia ser restringida pelo legislador, depositário da soberania popular, para viabilizar a convivência em sociedade, enquanto, por um lado, permitia que os direitos fundamentais funcionassem como garantias subjetivas frente ao Estado, ou mais propriamente, em face do Executivo, por outro, abria caminho para a tirania das maiorias, já que ainda não se concebia a vinculação do próprio legislador aos direitos fundamentais, que para ele só valiam como proposições programáticas ou eixos orientadores. A ideologia positivista publicista e legalista que acompanhava a visão liberal clássica do Estado trazia em seu bojo o enorme risco de uma tirania parlamentária das maiorias, à qual estava disponível o mecanismo irrefreável da lei, criador originário de direito e que não encontrava barreiras materiais na Constituição, nem mesmo nos direitos fundamentais que somente demandavam fundamento legal para sua restrição ${ }^{13}$.

Já nesse período weimariano, uma corrente minoritária, emergindo do movimento de revitalização da Teoria da Constituição, passou a rediscutir, com radicalidade, o tema dos direitos fundamentais, abrindo caminhos para que, posteriormente, se vislumbrasse a possibilidade de vinculação do próprio legislador ao conteúdo desses direitos, que não poderiam ser conformados $a b$ ovo por disposições infraconstitucionais. Começou-se a conceber o conjunto dos direitos fundamentais como a cristalização de ordem de valores ou de sistema cultural cunhando por um povo e do qual todo o ordenamento jurídico receberia a sua legitimação. Nessa perspectiva, inicia-se longa jornada de descoberta do que a dogmática alemã do pós-guerra viria a batizar de "caráter objetivo de valor dos direitos fundamentais" ${ }^{14}$.

No limite, a atribuição de caráter objetivo de valor aos direitos fundamentais leva a uma duplicação de sua estrutura: ao lado dos direitos fundamentais tradicionalmente concebidos como direitos subjetivos frente ao Poder Público, aparecem os direitos fundamentais como normas objetivas que expressam um conteúdo valorativo de vigência geral e um correspondente sistema de valores. Expressando essa realidade no contexto atual da dogmática alemã, Böckenförde resume:

A concepção atual dos direitos fundamentais se caracteriza por uma dupla qualificação de tais direitos. Os direitos fundamentais são concebidos, por um lado, como direitos subjetivos de liberdade, dirigidos ao Estado, do titular de direitos fundamentais, e, por outro e ao mesmo tempo $\square$, como normas objetivas de principio (objektive Grundsatznormen) e decisões axiológicas (Wertentscheidungen) que têm validade para todos os ámbitos do Direito. ${ }^{15}$

13 BÖCKENFÖRDE, Ernst Wolfgang. Escritos sobre derechos fundamentales. Baden-Baden: Nomos Verlagsgesellschaft, 1993. p. 97.

14 BÖCKENFÖRDE, Ernst Wolfgang. Escritos sobre derechos fundamentales. Baden-Baden: Nomos Verlagsgesellschaft, 1993. p 106 e seguintes.

15 BÖCKENFÖRDE, Ernst Wolfgang. Escritos sobre derechos fundamentales. Baden-Baden: Nomos Verlagsgesellschaft, 1993. p. 95. Tradução nossa. 
O caminho para essa configuração contemporânea dos direitos fundamentais foi cheio de percalços e muito contribuiu para desenrolar experiência do Tribunal Constitucional Federal Alemão e os aportes da doutrina especializada. Essa história, entretanto, não interessa para os fins da pesquisa proposta neste artigo. Interessa na realidade analisar mais detidamente um conceito, em alguma medida já descreditado e envelhecido, mas que muito contribuiu para essas transformações e que se considera bastante pertinente para que se compreenda o real sentido da Jurisprudência do Supremo Tribunal Federal sobre o tema escolhido. É o conceito de garantia institucional.

Antes mesmo que se visualizasse perfil objetivo dos direitos fundamentais, alguns autores perceberam que a Constituição garantia de maneira relativamente independente dos direitos nela previstos, certas formas jurídicas ou institutos, preservados de maneira que fossem identificáveis com a memória que a consciência social tivesse deles em cada momento e lugar. Entenderam que a Constituição preservaria a imagem social que cada momento histórico teria de uma instituição.

No cenário da República de Weimar, surgiu e alcançou a sua maior expressão no pensamento de Carl Schmitt, especialmente em sua "Teoria da Constituição" de 1928, o problemático conceito das garantias institucionais, para contemplar esse tipo de norma constitucional de perfil institucional, que não tinha como função primeira assegurar direitos subjetivos, e cujo detalhamento normativo, de ordinário, não era trazido pela própria Constituição, mas sim conformado, respeitando-se a tradição jurídica e o conteúdo histórico dos institutos, pela lei ordinária.

Segundo Paulo Bonavides:

A garantia institucional visa, em primeiro
lugar, assegurar a permanência da institui-
ção, embargando-lhe a eventual supressão
ou mutilação e preservando invariavelmente
o mínimo de substantividade ou essenciali-
dade, a saber, aquele cerne que não deve ser
atingido nem violado, porquanto se tal acon-
tecesse, implicaria já o perecimento do ente
protegido ${ }^{16}$.

Esse conceito pressupunha visão da Constitui-

16 BONAVIDES, Paulo. Curso de direito constitucional. 25. ed. São Paulo: Malheiros, 2010. p. 542. ção como garantidora não somente de direitos subjetivos ou de mecanismos de proteção desses direitos, mas de valores e de tradições caros a uma determinada sociedade e de formas jurídicas preexistentes, úteis para o cumprimento de determinadas funções e para a satisfação de determinados interesses.

Nos termos de Canotilho: "sob o ponto de vista da proteção jurídica constitucional, as garantias institucionais não garantem aos particulares posições subjetivas autônomas e daí a inaplicabilidade do regime dos direitos, liberdades e garantias [subjetivas]." ${ }^{17}$.

As garantias institucionais representaram, na história do pensamento constitucional, uma das primeiras tentativas de superação da concepção positivista de supremacia do Legislativo e de vinculação da lei ao conteúdo material da Constituição e não apenas à sua face procedimental e de distribuição de competências. Com esse conceito, Schmitt buscou defender que era vedada ao legislador a intervenção que desnaturalizasse determinados institutos e instituições clássicas do direito nacional, a ponto de torná-los irreconhecíveis, inviabilizando a função ordenadora, que tradicionalmente cumpriram, ou impedindo a tutela dos valores por eles corporificados.

Sobre a garantia institucional, Pastor Santamaría afirma que:

[...] trata-se, pois, de uma técnica de proteção, face ao legislador e aos outros poderes públicos, daquelas instituições de cuja regulamentação no texto fundamenal é possível deduzir-se que desempenham um papel estruturante básico na conformação e desenvolvimento da orden institucional; uma técnica de proteção que atua não somente face às tentativas de supressão, mas também face a quaisquer tipos de ações públicas que desvirtuem ou desnaturalizem o seu núcleo esencial. ${ }^{18}$

A teoria das garantias institucionais, na esteira das preocupações com a tirania do parlamento influenciou o subsequente descobrimento do caráter objetivo dos direitos fundamentais. Em verdade, a teoria institucional, que surge, nesse momento, desvinculada dos direitos fundamentais, os quais, a essa

17 CANOTILHO, 1991 apud BONAVIDES, Paulo. Curso de direito constitucional. 25. ed. São Paulo: Malheiros, 2010. p. 545.

18 SANTAMARÍA PASTOR, J. A. Fundamentos de derecho administrativo. Madrid: Centro de Estudios Ramón Areces, 1988. p. 460. Tradução nossa. 
altura, só eram visualizados no seu perfil subjetivo, abriu caminho para o que parecia ser uma justificação da proteção constitucional desses direitos mais adequada do que aquela que era oferecida pela tradição liberal. Em um contexto comunitário no qual começavam a emergir as preocupações sociais no âmbito da Constituição, como legitimar a proteção que a Carta Magna proporcionava aos direitos subjetivos, à propriedade e à herança, por exemplo? Estando em decadência a explicação jusnaturalista da preexistência dos direitos ao ordenamento estatal, explicação que se enfraquecera, precisamente, pelo movimento de positivação desses direitos, que ela mesma inspirara, como evitar que os direitos subjetivos adquirissem o caráter de odiosos privilégios? Um caminho consistia em funcionalizá-los ou desvelar o seu caráter institucional, de elementos gerais ordenadores da convivência social, à maneira do que vinha acontecendo com as garantias institucionais.

A esse respeito, Márcio Iório nos explica:

[...] Justamente por se especificarem frente aos direitos individuais clássicos do status negativus, as garantias institucionais dão um colorido novo às salvaguardas constitucionais de certos status, utilizando-se a terminologia de Schmitt. Aqueles direitos deixam de ser considerados como pretensões individuais de titulares pontualmente isolados, no que não haveria como deixar de ver um privilégio constitucional, e passam a integrar a proteção objetiva de institutos cristalizados em plexos normativos constitucionais. A especificidade de tratamento justifica-se, portanto, enquanto represente o interesse público de proteção institucional, e nunca o interesse de momento de uma determinada maioria parlamentar.

A garantia institucional adquire, assim, uma função conformadora dos direitos fundamentais, na medida em que transparece o contexto e, com isso, as fronteiras objetivas em que ditos direitos são envolvidos em determinado momento histórico. ${ }^{19}$

Entretanto, ao emergir desse cenário de tentativa de superação do paradigma do Estado Liberal clássico, a crítica de Schmitt, profundamente radical, acabou por inverter os polos da antinomia público e privado, em vez de buscar reequilibrá-los, concebendo a esfera individual de liberdade como originaria-

19 ARANHA, M. I. Interpretação constitucional e as garantias institucionais dos direitos fundamentais. 2. ed. São Paulo: Atlas, 2000. p. 181-182. mente conformada por uma visão do bem comum, ou do interesse público.

O problema se agrava quando, com a emergência do Estado Social, essa visão do bem comum passa a ser delimitada por uma burocracia tecnocrata judicial ou administrativa, infensa ao controle dos cidadãos. Em verdade, os cidadãos, no modelo do Estado Social de Direito, reduziam-se a meros clientes destinatários dos serviços e dos bens fornecidos pelo aparelho estatal, que definia, em nome de todos, quais as necessidades a serem atendidas e concentrava em si mesmo todo o sentido do público.

Antecipando a ideologia do Estado Social, a teoria constitucional das garantias institucionais, ao menos em sua conformação original, representou risco para a preeminência dos direitos individuais. Essa concepção ensejava a atuação paternalista do Poder Público na manutenção e na proteção de ordem de valores, de moralidade pública, de tradição ética, ou de determinados fins sociais, como estes eram entendidos pelo Judiciário e pela doutrina majoritária, bem como de uma herança conceitual, que, em muitas ocasiões, conflitava com liberdades individuais concretas. Esse problema se agravava quando se pressupunha a anterioridade das instituições à própria Constituição, compreendendo-se por isso a sua preexistência e caráter ilimitado, concepção que não foi nem mesmo defendida por Schmitt, como percebemos a partir da seguinte passagem mencionada por Rodríguez-Armas:

A garantia institucional é, por sua essência, limitada. Existe somente dentro do Estado, e se baseia, não na ideia de uma esfera de liberdade ilimitada em principio, uma vez que é afeta a uma instituição jurídicamente reconhecida, que, como tal, é sempre uma coisa circunscrita e delimitada, a serviço de certas tarefas e de certos fins, ainda quando as tarefas não estejam especializadas em particular e seja admissível uma certa universalidade do círculo de atuação. ${ }^{20}$

Apesar de não ser endossada pelo próprio criador da teoria das garantias institucionais, a visão extremada da sua preexistência e da sua prevalência sobre a própria Constituição e sobre os direitos por ela assegurados constitui desvio bastante comum e de

20 RODRÍGUEZ-ARMAS, Magdalena Lorenzo. Análisis del contenido esencial de los derechos fundamentales enunciados en el art. 53.1 de la constitución española. Granada: Comares, 1996. p. 180. 
graves consequências. A exacerbação do perfil institucional da Constituição, assim como a liberdade sem limites da leitura liberal clássica dos direitos são visões parciais e enviesadas de uma mesma realidade. Ambas acarretam perigosas distorções de entendimento e produzem grave desequilíbrio na teoria dos direitos.

Como explica Bonavides:

[...] na problemática da garantia institucional, toda resposta afirmativa da anterioridade da instituição, se não for mantida uma certa cautela, poderá eventualmente conduzir a uma distorção de entendimento, que favoreça a supremacia abusiva do Estado e sacrifique a preeminência dos direitos fundamentais.

Em verdade, o mesmo que aconteceu outrora com a teoria dos direitos fundamentais cuja prevalência ilimitada ocasionou graves danos à introdução dos direitos sociais, ao mesmo tempo que retardou o advento do primado dos interesses da sociedade sobre os do indivíduo, poderá também ocorrer, por outro lado, se os poderes estabelecidos proclamarem, em termos de valores absolutos, a supremacia das instituições, eventualmente legitimadoras da razão de Estado. Aqui a vítima, ao contrário, não seria a sociedade, mas o cidadão e suas liberdades. ${ }^{21}$

Até mesmo Schmitt, como corolário de sua paixão pelo homogêneo e pelo nacional, deu demasiado relevo ao aspecto objetivo dos direitos, desvalorizando o espaço de proteção privada dos indivíduos, o que levou, ao fim e ao cabo, à destituição de qualquer caráter limitativo às suas garantias institucionais, permitindo que assumissem qualquer conteúdo, inclusive o de tradições excludentes e arbitrárias. ${ }^{22}$.

Incluídas dentre as garantias institucionais, estariam as garantias do instituto, nas quais o objeto de proteção se originaria dos clássicos institutos de direito privado, assim entendidos a propriedade, a família, a regras de sucessão etc. Embora mantivessem a sua origem relacionada aos institutos civilistas tradicionais, elas se deslocariam, enquanto núcleos de sentido concreto, historicamente definidos, para dentro do ordenamento jurídico, destacando-se da autorregulamentação feita pelos particulares e tor-

21 BONAVIDES, Paulo. Curso de direito constitucional. 25. ed. São Paulo: Malheiros, 2010. p. 538.

22 ARANHA, M. I. Interpretação constitucional e as garantias institucionais dos direitos fundamentais. 2. ed. São Paulo: Atlas, 2000. p. 180. nando-se objetivas. Segundo essa concepção, seriam contrárias à Constituição normas editadas pelos poderes públicos ou pactuadas pelos agentes privados que se afastassem, radicalmente, da conformação tradicionalmente dada, pelo direito, a esses institutos, ofendendo o que a doutrina entendia como componente do seu "núcleo essencial" ou os seus requisitos característicos, o que levaria a sua desnaturação, ou ao esvaziamento de seu "sentido objetivo" ${ }^{23}$.

\section{0 casamento como garantia do instituto na jurisprudência do STF}

A teoria constitucional das garantias institucionais, em sua primeira versão, como já referido, pretendendo ampliar o horizonte de proteção e de garantia encampado pelo Direito Constitucional, que, no paradigma do Estado Liberal, apenas se restringia à guarda de liberdades individuais, acaba por cristalizar as fronteiras dos direitos, amarrando-os a certos valores, materializados em institutos, supostamente objetivos e representativos do contexto em que estariam inseridos.

Aplicando-a ao caso em questão, aconteceria que o direito de optar pela forma de estruturação do afeto, ou seja, a liberdade afetiva (ou afetividade) seria restringida pela concepção da monogamia, da exclusividade sexual, como componente do núcleo essencial da família como garantia institucional. E o casamento, nesse contexto, seria entendido como forma suprema, purificada dessa garantia institucional.

A Corte Constitucional brasileira afirmou esse entendimento a respeito da família como garantia institucional na decisão do RE no 397.762-8 - BA, impossibilitando o reconhecimento das uniões estáveis simultâneas ou paralelas, como entidades familiares.

A articulação desse entendimento se explicita na seguinte passagem do voto do Ministra Cármen Lúcia quando pondera que é preciso procurar fazer justiça no caso concreto: "mas sem abrir mão nunca de saber que aqui temos de racionalizar até em benefício do equilíbrio de todas as instituições, uma das quais, o casamento". ${ }^{24}$

23 PIEROTH, Bodo; SCHLINK, Bernhard. Direitos fundamentais: direito estadual II. São Paulo, Saraiva, 2011. p. 119.

24 BRASIL. Supremo Tribunal Federal. Recurso Extraordinário. RE 397762 BA. Primeira Turma. Recorrente: Estado 
De fato, ainda sem mencionar expressamente a teoria das garantias institucionais, os Ministros estabeleceram o bloco de constitucionalidade (normas que servem como referência ou parâmetro de controle da conformidade à Constituição) para abranger a legislação infraconstitucional delimitadora do perfil essencial da instituição da família no Direito Brasileiro. Com esse bloco de constitucionalidade ampliado, para atribuir às normas de Direito de Família, status constitucional, ainda que não formalmente, foi afastada a possibilidade de reconhecimento de famílias simultâneas.

O referido raciocínio fica patente no seguinte posicionamento:

[trecho do voto do Ministro Menezes Direito] [...] a disciplina constitucional foi muito clara, ela determinou que a proteção do Estado fosse oferecida quando configurada a existência de uma união estável, tanto que determinou a facilitação legal para o matrimônio, ou seja, numa palavra, ele estendeu a proteção constitucional à entidade familiar denominada união estável no campo do Direito de Família, ou seja, mandou aplicar o Direito de Família a essa entidade familiar que ele qualificou no $\$ 3^{\circ}$ do artigo 226; segundo quando ele determinou que essa proteção constitucional a essa entidade familiar, união estável, fosse dada no campo do Direito de Família, evidentemente, que ele quis sublinhar que se aplicavam os princípios do Direito positivo infraconstitucional para discutir a matéria relativa a essa nova entidade familiar; [...] O que se está interpretando é a constituição nos termos em que ela determinou que o direito positivo assim o fizesse. E o direito positivo, seguindo o próprio comando constitucional, determinou os balizamentos pelos quais seria possível haver o reconhecimento da união estável. E, certamente, um desses balizamentos não foi obedecido, que é a ausência de impedimento para a realização de casamento, no caso, a manutenção do casamento contraído, sem a existência da separação de fato. ${ }^{25}$

Fica claro que a compreensão dos Ministros

da Bahia. Recorrido: Joana da Paixão Luz. Relator: Min. Marco Aurélio. Brasília, 03 de junho de 2008. Disponível em: <http://stf.jusbrasil.com.br/jurisprudencia/2918741/ recurso-extraordinario-re-397762-ba $>$. Acesso em: 17 set. 2015.

25 BRASIL. Supremo Tribunal Federal. Recurso Extraordinário. RE 397762 BA. Primeira Turma. Recorrente: Estado da Bahia. Recorrido: Joana da Paixão Luz. Relator: Min. Marco Aurélio. Brasília, 03 de junho de 2008. Disponível em: $<$ http://stf.jusbrasil.com.br/jurisprudencia/2918741/recurso-extraordinario-re-397762-ba>. Acesso em: 17 set. 2015. que formaram a maioria no referido julgamento parece ser a de que o casamento, manifestação mais completa da garantia institucional da família, pressupõe a monogamia, como valor fundante, e que não há família que possa escapar a esse paradigma sem sofrer uma redução de status.

Curioso perceber que a mesma razão de decidir, estendendo-se o bloco de constitucionalidade ao Direito de Família construído pelo legislador ordinário, não foi aplicada no caso da $\mathrm{ADPF} n^{\circ} 132-\mathrm{RJ}$, que reconheceu a união homoafetiva, fazendo interpretação conforme a Constituição do art. 1723 do Código Civil, a qual se aproximou de uma verdadeira interpretação evolutiva ou mesmo do reconhecimento de uma mutação constitucional, uma vez que o referido artigo não passa de um decalque do art. $226, \S 3^{\circ}$ da Carta da República.

Não há como negar que há, com base nessa perspectiva, patente inconsistência na Jurisprudência do STF. Em que medida o reconhecimento de uniões homoafetivas também não atentaria como a garantia institucional da família? Como seria possível reconhecer a sua constitucionalidade aplicando-se o mesmo parâmetro de controle que foi empregado no RE no 397.762-8 - BA, abrangendo a legislação de Direito de Família? Apenas três anos separam as duas decisões, mas a mudança de orientação é radical. A flutuação do entendimento da Suprema Corte, inevitavelmente, produz insegurança jurídica e esvazia a sua fonte de legitimidade, que reside na integridade da sua fundamentação.

Em seu emblemático voto na ADPF n 132-RJ, o Ministro Relator Carlos Ayres Britto afirma a precedência do livre desenvolvimento da personalidade, no âmbito afetivo e sexual, sobre a moralidade comunitária, sintetizando, por outro lado, os limites dessa liberdade afetiva na seguinte passagem:

É ajuizar: seja qual for a preferência sexual das pessoas, a qualificação dessa preferência como conduta juridicamente lícita se dá por antecipação. [...] O que já põe o Direito em estado de alerta ou de especiais cuidados para não incorrer na temeridade de regulamentar o factual e axiologicamente irregulamentável. A não ser quando a sexualidade de uma pessoa é manejada para negar a sexualidade da outra, como sucede, por exemplo, com essa ignominiosa violência a que o Direito apõe o rótulo de estupro. $\mathrm{Ou}$ com o desvario ético-social da pedofilia e do 
incesto. Ou quando resvalar para a zona legalmente proibida do concubinato. ${ }^{26}$

Ora, o núcleo da argumentação vitoriosa na ADPF no 132-RJ pode ser assim resumido: não existem liberdades absolutas, no entanto, todo direito fundamental só pode ser restringido de forma proporcional e razoável, em face de outros direitos fundamentais ou bens jurídicos constitucionalmente protegidos. A violência sexual, a toda evidência, deve ser vedada pelo ordenamento, porque ofende direitos individuais bem delimitados. O mesmo poder-se-ia dizer da pedofilia, sem maiores discussões. Mas e quanto ao concubinato? A união homoafetiva foi considerada constitucional porque não haveria "qualquer interesse legítimo" que justificasse o seu não reconhecimento. Esse reconhecimento "não afeta qualquer direito de terceiros ou bem jurídico que mereça proteção constitucional" 27 . Não seria possível dizer o mesmo do concubinato? Que direito ou interesse legítimo de terceiro seria afetado com a sua elevação ao status de família? O patrimônio moral e material da família oficial? Mas haveria dever do(a) concubino(a), derivado da boa-fé objetiva, de não interferir em uniões já constituídas ou o dever de fidelidade e lealdade seria somente do cônjuge ou do companheiro e não do terceiro integrante da família simultânea?

Se o Supremo Tribunal Federal tivesse decidido, com a mesma perspectiva liberal que à primeira vista, foi adotada na $A D P F n^{\circ} 132-R J$ o precedente das famílias simultâneas, por coerência, não haveria de ter reconhecido o status constitucional do paralelismo afetivo? Não o fez, como observamos analisando a fundamentação do julgado, não porque os direi-

26 BRASIL. Supremo Tribunal Federal. Arguição de Descumprimento de Preceito Fundamental. ADPF 132 - RJ. Tribunal Pleno. Arguente: Governo do Estado do Rio de Janeiro. Arguidos: Governador do Estado do Rio de Janeiro, Assembleia Legislativa do Estado do Rio de Janeiro e Tribunais de Justiça dos Estados. Relator: Min. Ayres Britto. Brasília, 05 de maio de 2011. Disponível em: <http:// redir.stf.jus.br/paginadorpub/paginador.jsp?docTP=AC\&docID $=628633>$. Acesso em: 17 set. 2015.

27 BRASIL. Supremo Tribunal Federal. Arguição de Descumprimento de Preceito Fundamental. ADPF 132 - RJ. Tribunal Pleno. Arguente: Governo do Estado do Rio de Janeiro. Arguidos: Governador do Estado do Rio de Janeiro, Assembleia Legislativa do Estado do Rio de Janeiro e Tribunais de Justiça dos Estados. Relator: Min. Ayres Britto. Brasília, 05 de maio de 2011. Disponível em: <http:// redir.stf.jus.br/paginadorpub/paginador.jsp?docTP=AC\&docID=628633 $>$. Acesso em: 17 set. 2015 . tos da família oficial estariam sendo afetados, embora se tenha explicitamente debatido a respeito, mas porque uma decisão nesse sentido ofenderia a família como garantia institucional, mecanismo empregado para ampliar o bloco de constitucionalidade à própria legislação infraconstitucional. No limite, uma decisão nesse sentido ofenderia a imagem socialmente reconhecível de família.

Mas o reconhecimento de uniões homoafetivas também não se afastaria da tradição familiar? Como superar essa incongruência na fundamentação das duas decisões? Isso só foi possível, porque, conforme se há de ver, a Suprema Corte, na ADPF no 132-RJ, apesar de em uma primeira leitura parecer o contrário, também fundamentou a sua decisão em uma revitalização do conceito de família como garantia institucional, para que abrangesse as uniões homoafetivas. Se essa construção jurisprudencial foi possível, também não seria possível a sua ampliação para alcançar as famílias simultâneas?

\section{Uma nova garantia do instituto da família?}

Partindo-se da concepção da família como garantia do instituto, nos termos do que parece ser o entendimento do Supremo Tribunal Federal, como se veio defendendo, não haveria possibilidade de conciliá-la com a tutela jurídica do paralelismo afetivo como foi ela conciliada com as uniões homoafetivas?

Atualmente, há os que propõem uma revisitação da teoria das garantias institucionais, mais adequada à interpretação do Direito no paradigma do Estado Democrático, em que a autonomia privada e a autônima pública, a liberdade e a igualdade, são consideradas co-originárias ou equiprimordiais, conciliando-se a segurança da forma do direito com sua abertura procedimental. Sobre o papel das garantias institucionais, nessa versão contemporânea da teoria institucional, Márcio Iório nos fala:

Refletem uma dupla função: elas objetivam conteúdos jurídicos, enquanto referência dinâmica de evolução do sistema, e, com isso, agem como elemento instituidor; por outro lado, elas preservam um conteúdo já assimilado e objetivamente cristalizado, e com isso atuam como elemento instituído (eingerichtet). O essencial em seu conceito está justamente em não transigir com o aparente antagonismo dos dois momentos, e, com isso, 
pretende promover-lhes uma coexistência pacífica. A teoria institucional transmite a constatação de que os momentos instituidor e instituído não podem prescindir um do outro. A existência de cada qual depende de sua abertura periódica à ingerência de seu antagônico. Se a função da constituição é a de dar estabilidade às instituições, mas se tal estabilidade não resulta estática, ela deve ser reconhecida em seu dinamismo. ${ }^{28}$

$\mathrm{Na}$ sua concepção originária, as garantias institucionais eram conceptualmente distintas dos direitos fundamentais, razão pela qual propiciavam a sua conformação ao contexto histórico-social e a delimitação de suas fronteiras. Elas possuíam "um sujeito e um objeto diferente dos direitos dos cidadãos" ${ }^{29}$, ou seja, as destinatárias de sua proteção eram as próprias instituições como realidades sociais objetivas, só indiretamente assegurando direitos individuais. Já a nova leitura das garantias institucionais pretende contemporizar o seu aspecto socializante e objetivante dos direitos com a liberdade e autonomia individuais. Dessa forma, o instrumental teórico das garantias institucionais estaria apto a manter a sua utilidade operacional em um contexto pluralista, participativo e multicultural. Resumindo, a evolução doutrinária que desaguou nessa versão atualizada da teoria de Schmitt, Bonavides nos diz:

[...] o Estado Social produziu, porém vínculos entre as instituições e os novos direitos fundamentais mediante renovação doutrinária, que fez semelhantes direitos gravitarem quase todos na órbita social. E a teoria das garantias institucionais não pôde desfazer-se dos laços que a prendem aos direitos fundamentais, sem embrago de todo empenho havido em separar direitos e garantias.

Essa conexidade só deixaria de existir e de ocorrer se baníssemos das garantias institucionais as garantias do instituto. Mas esse expurgo não é fácil, nem todos o aceitam. São as garantias do instituto que formam o componente institucional dos direitos fundamentais. $^{30}$

Com a consciência de que é exatamente no campo das garantias do instituto que a interdependência entre os direitos fundamentais e as garantias institu-

28 ARANHA, M. I. Interpretação constitucional e as garantias institucionais dos direitos fundamentais. 2. ed. São Paulo: Atlas, 2000. p. 197-198.

29 CANOTILHO, J. J. Gomes. Direito constitucional e teoria da constituição. 5. ed. Coimbra: Almedina, 1991. p. 438.

30 BONAVIDES, Paulo. Curso de direito constitucional. 25. ed. São Paulo: Malheiros, 2010. p. 545-546. cionais sobressai, alguns juristas e juízes estão trabalhando no sentido de calibrar a garantia do instituto da família com os direitos fundamentais da liberdade afetiva, da dignidade humana e da busca da felicidade, afirmados pela nova ordem constitucional. Essa tentativa necessariamente implica a superação do paradigma do matrimônio como forma perfeita e ideal de uma entidade familiar. Mas não somente isso.

Exemplo de pensador a trabalhar nesse front Carlos Pianovski Ruzyk tem uma abordagem do problema, que traz elementos e propostas interessantes para uma possível solução. Ele parte do pressuposto de que o modelo unificado do antigo Código Beviláqua, que garantia como única forma familiar legítima o casamento civil, ou o casamento de outra maneira reconhecido pelo Estado, teria sido superado e substituído por um modelo constitucional pluralista e de liberdade afetiva. Essa transformação do tratamento dado às famílias pelo direito não resultaria de uma decadência moral ou da exacerbação de um individualismo hedonista e irresponsável, mas, pelo contrário:

Se a família é instrumento de desenvolvimento da personalidade, de concretização da dignidade da pessoa humana, resta evidente que não é de um individualismo utilitarista que se está a tratar. Se a proteção deve se dirigir à pessoa de cada um dos membros da família e, se estes não podem ser tomados como indivíduos atomizados, mas, sim, como entes em relação de coexistência, resta claro que, apresentada uma situação de simultaneidade familiar, o sentido dessa proteção deve atender à inter-relação entre aqueles que nela se inserem. ${ }^{31}$

Não caberia ao Estado, com o instrumental do Direito de Família, eleger padrão a ser obedecido como única forma passível de tutela jurídica, marginalizando condutas desviantes. Ao Poder Público, não caberia esse "lugar de interdição", como superego da sociedade e bastião da "moral social média". Impossível seria, por isso, reconhecer-se um princípio da monogamia como um mandamento do Estado invadindo a esfera mais sensível da autonomia privada individual e afetando as suas escolhas mais pessoais, imprescindíveis para o "livre desenvolvimento de sua subjetividade." 32

31 RUZYK, Carlos Eduardo Pianovski. Famílias simultâneas: da unidade codificada à pluralidade constitucional. Rio de Janeiro: Renovar, 2005. p. 27-28.

32 RUZYK, Carlos Eduardo Pianovski. Famílias Simultâneas e Monogamia. In: CONGRESSO BRASILEIRO DE DIREITO DE FAMÍlIA, 5., 2006, Belo Horizonte. Família e dig- 
Se a lei, em sentido lato, pode impor um dever de monogamia, é somente no sentido da vedação da constituição de "duas ou mais uniões formais" ao mesmo tempo, ou seja, de "duas ou mais relações matrimonializadas", constituídas sob a "chancela prévia do Estado”. Não poderia, a priori, e, em caráter absoluto, abarcar uniões de fato, sob a pena de servir o Estado de "tutor da construção afetiva coexistencial", papel que lhe foi desautorizado pela nova ordem constitucional. ${ }^{33}$

O reconhecimento de entidades familiares, a seleção dos critérios para a sua configuração, não poderia ser determinado por parâmetros prévios, excludentes da "construção normativa realizada em concreto", pelos próprios interessados, livremente estruturando as suas relações de afeto na família, "espaço privilegiado de desenvolvimento da personalidade". O sistema constitucional, como totalidade aberta, deve possibilitar o ingresso amplo das mais diversas formações familiares, inclusive as marcadas pelo paralelismo afetivo. ${ }^{34}$

É, nesse ponto, que se introduz o argumento mais interessante para os fins do nosso trabalho. Ruzyk enfrenta, diretamente, a questão da família como instituição, para afirmar que ela só faz sentido se entendermos que não é a própria família o lugar "abstrato e transpessoal" destinatário da proteção jurídica, mas sim espaço de "relação coexistencial concreta de seus componentes", ou seja, espaço em que se viabiliza a "incidência dos direitos fundamentais nas relações interprivadas”. O modelo familiar não é importante, mas mero "instrumento das pessoas que nele se inserem". Com isso, não se quer dizer, no entanto, que seja instrumento de realização do desejo ou de pulsões egoísticas de um indivíduo sobre o outro, mas sim de uma "busca da felicidade compartilhada e coexistencial." ${ }^{35}$ Em suas próprias palavras:

nidade humana: Anais... São Paulo: IOB Thomson, 2006. p. 193-221. p. 198.

33 RUZYK, Carlos Eduardo Pianovski. Famílias Simultâneas e Monogamia. In: CONGRESSO BRASILEIRO DE DIREITO DE FAMÍLIA, 5., 2006, Belo Horizonte. Família e dignidade humana: Anais... São Paulo: IOB Thomson, 2006. p. 193-221.

34 RUZYK, Carlos Eduardo Pianovski. Famílias Simultâneas e Monogamia. In: CONGRESSO BRASILEIRO DE DIREITO DE FAMÍLIA, 5., 2006, Belo Horizonte. Família e dignidade humana: Anais... São Paulo: IOB Thomson, 2006. p. 193-221. p. 199.

35 RUZYK, Carlos Eduardo Pianovski. Famílias Simultâneas e Monogamia. In: CONGRESSO BRASILEIRO DE DIREITO DE FAMÍLIA, 5., 2006, Belo Horizonte. Família e dignidade humana: Anais... São Paulo: IOB Thomson, 2006. p. 193-221. p. 201.
A perspectiva protetiva eudemonista da Constituição se dirige à concretude da vida, e não a uma abstração. Não há uma tutela do lugar abstrato institucional, nem, tampouco, do indivíduo atomizado. Note-se que tomar a individualidade do sujeito de modo isolado das relações concretas que ele trava, a todo o momento, também é conduta tendente à abstração.

Nesse sentido, a tutela jurídica à busca da felicidade por meio da família diz respeito a uma felicidade coexistencial, e não puramente individual. Por evidente, não se trata o eudemonismo constitucional de busca hedonista pelo prazer individual, que transforma o outro em instrumento da satisfação do eu. Se a relação familiar pode ser vista como instrumento, os entes que a compõem não são objetos uns dos outros. Uma concepção desse jaez aviltaria a dignidade dos componentes da família, por meio da reificação. O dever ser da família impõe respeito e proteção mútua da dignidade coexistencial de seus componentes ${ }^{36}$.

No entanto, Ruzyk fala de algumas restrições ao amplo reconhecimento de efeitos jurídicos aos relacionamentos paralelos, que devem ser feitas, não em abstrato, mas, com base na casuística que se apresentar ao eventual julgador. Como o dever de proteção de cada entidade familiar implica que a família deve ser um espaço de "arranjos afetivos que atendam à dignidade intersubjetiva de seus componentes", “impõe-se analisar as manifestações de simultaneidade familiar também sob uma perspectiva que recolha eventuais repercussões juridicamente relevantes dessa situação de fato para os componentes que não integram aquela mesma entidade familiar - ou seja, para os que integram o outro núcleo que se põe em condição de simultaneidade." 37

Isso ocorre porque a proteção à realização dos desejos dos componentes de um desses núcleos poderia, na opinião do autor, resultar em grave violação à dignidade dos integrantes do outro grupo. É assim que o referido autor vê a imposição pelo ordenamento jurídico brasileiro de um "dever de respeito

36 RUZYK, Carlos Eduardo Pianovski. Famílias Simultâneas e Monogamia. In: CONGRESSO BRASILEIRO DE DIREITO DE FAMÍLIA, 5., 2006, Belo Horizonte. Família e dignidade humana: Anais... São Paulo: IOB Thomson, 2006. p. 193-221. p. 207.

37 RUZYK, Carlos Eduardo Pianovski. Famílias Simultâneas e Monogamia. In: CONGRESSO BRASILEIRO DE DIREITO DE FAMÍlIA, 5., 2006, Belo Horizonte. Família e dignidade humana: Anais... São Paulo: IOB Thomson, 2006. p. 193-221. p. 209-210. 
à boa-fé objetiva"38, também no âmbito do paralelismo afetivo:

[...] isso implica dizer que o direito pode não proteger aquele que, a pretexto da satisfação egoística do próprio desejo, aniquila a dignidade do outro, mediante um proceder iníquo e desleal, que frustra as expectativas de coexistência afetiva nutridas por conta da relação de conjugalidade entre eles mantida.

Do mesmo modo, aquele que, ciente de que está a manter relação de conjugalidade com pessoa que já compõe um núcleo familiar anterior, procede de modo a desprezar qualquer dever ético perante os componentes da primeira entidade familiar, pode não ter plenamente atendidas suas expectativas acerca de eventual chancela jurídica da relação por ele mantida, se essa eficácia vier a intervir na esfera jurídica dos membros do outro núcleo familiar.

O sentido ético que na análise do caso concreto pode obstar parcialmente a eficácia jurídica de uma situação de simultaneidade familiar pode ser inferido do princípio da boa-fé objetiva. ${ }^{39}$

Perceba-se que, apesar de arrostar, diretamente, a questão da família como garantia institucional, utilizando-se da doutrina da boa-fé objetiva, o referido autor acaba voltando à mesma imposição de um dever ético de respeitar a relação constituída em primeiro lugar, acabando por privilegiar, por outros meios, o princípio monogâmico. Sua concepção, entretanto, já é um grande avanço no sentido da afirmação do paralelismo afetivo, uma vez que o requisito da boa-fé objetiva pode ser atendido em uniões não monogâmicas transparentes, em que todos os componentes de cada núcleo afetivo simultâneo estejam plenamente conscientes de que mantêm um membro em comum e consintam livremente com esse fato. São os casos de poliamorismo, em que a ostensibilidade plena parece sugerir que a situação de simultaneidade satisfaz as legítimas expectativas de confiança e as "pretensões de felicidade existencial de todos os envolvidos." ${ }^{40}$

38 RUZYK, Carlos Eduardo Pianovski. Famílias Simultâneas e Monogamia. In: CONGRESSO BRASILEIRO DE DIREITO DE FAMÍLIA, 5., 2006, Belo Horizonte. Família e dignidade humana: Anais... São Paulo: IOB Thomson, 2006. p. 193-221. p. 210.

39 RUZYK, Carlos Eduardo Pianovski. Famílias Simultâneas e Monogamia. In: CONGRESSO BRASILEIRO DE DIREITO DE FAMÍlIA, 5., 2006, Belo Horizonte. Família e dignidade humana: Anais... São Paulo: IOB Thomson, 2006. p. 193-221. p. 210.

40 RUZYK, Carlos Eduardo Pianovski. Famílias Simultâneas e Monogamia. In: CONGRESSO BRASILEIRO DE DIREITO DE FAMÍlIA, 5., 2006, Belo Horizonte. Família e dignidade humana: Anais... São Paulo: IOB Thomson, 2006. p. 193-221. p. 212.
A construção de Ruzyk é inovadora, mas não se trata de uma iniciativa isolada. E nem mesmo de um esforço doutrinário sem eco jurisprudencial. Na realidade, na já referida ADPF no 132-RJ o Ministro Luiz Fux, em seu voto no sentido do reconhecimento das uniões entre pessoas do mesmo sexo como entidades familiares, propõe uma verdadeira reformulação da concepção da família como garantia do instituto, nos seguintes termos:

[...] como é cediço, o art. 226, caput, da Constituição de 1988 estabelece que a família, como base da sociedade tem especial proteção do Estado. Trata-se de uma garantia institucional [...] A consagração da garantia institucional da família serve à preservação do instituto como ambiente e veículo de realização dos direitos fundamentais. [...] a Constituição de 1988 consagrou a família como instrumento de proteção da dignidade dos seus integrantes e do livre exercício dos direitos fundamentais, de modo que, independentemente de sua formação quantitativa ou qualitativa -, serve o instituto como meio de desenvolvimento e garantia da existência livre e autônoma dos seus membros.

Dessa forma o conceito constitucional pós-1988 de família despiu-se de materialidade e restringiu-se a aspectos meramente instrumentais, merecendo importância tão-somente naquilo que se propõe à promoção e à proteção dos direitos fundamentais dos indivíduos. Em síntese, não pode haver compreensão constitucionalmente adequada do conceito de família que aceite o amesquinhamento dos direitos fundamentais. $^{41}$

A leitura do Ministro Fux é, à primeira vista, uma subversão do conceito das garantias institucionais, pois, de fato, se um instituto for despido de toda a sua materialidade, ou seja, de qualquer conteúdo objetivado e cristalizado na sua evolução histórica, o seu elemento institucional desaparece e ele sobrevive como mera forma disponível aos interessados em dele se valerem. Entretanto, mais adiante em seu voto, o Ministro pergunta o que caracterizaria, do ponto de vista "ontológico", essencialmente, a família e apresenta a seguinte resposta:

O que faz a família é, sobretudo, o amor não a mera afeição entre os indivíduos, mas

${ }^{41}$ BRASIL. Supremo Tribunal Federal. Arguição de Descumprimento de Preceito Fundamental. ADPF 132 - RJ. Tribunal Pleno. Arguente: Governo do Estado do Rio de Janeiro. Arguidos: Governador do Estado do Rio de Janeiro, Assembleia Legislativa do Estado do Rio de Janeiro e Tribunais de Justiça dos Estados. Relator: Min. Ayres Britto. Brasília, 05 de maio de 2011. Disponível em: <http:// redir.stf.jus.br/paginadorpub/paginador.jsp?docTP=AC\&docID $=628633>$. Acesso em: 17 set. 2015 
o verdadeiro amor familiar, que estabelece relações de afeto, assistência e suporte recíprocos entre os integrantes do grupo. O que faz uma família é a comunhão, a existência de um projeto coletivo, permanente e duradouro da vida em comum. O que faz uma família é a identidade, a certeza de seus integrantes quanto à existência de um vínculo inquebrantável que os une e que os identifica uns perante os outros e cada um deles perante a sociedade. Presentes esses três requisitos, tem-se uma família, incidindo, com isso, a respectiva proteção constitucional. ${ }^{42}$

Assim, algumas linhas adiante, o Ministro Fux ressuscita a garantia institucional da família, que ele havia acabado de anular, reconhecendo-lhe um novo conteúdo, mais adequado ao seu contexto, mas ainda assim, atribuindo-lhe uma "essência", ainda que "transitória" ou "historicamente construída". Esse conceito de família engloba não apenas as uniões homoafetivas, como era o propósito do caso em questão, mas pode servir também para incluir, no âmbito de proteção constitucional, as situações de paralelismo afetivo. Toda a questão se resume a encontrar, em cada uma das uniões conduzidas simultaneamente, os elementos constitutivos da família: a comunhão, o amor familiar e a identidade. Para identificá-los, há alguns sinais da experiência comum, mas esses são apenas indícios, afinal todos podem amar livremente, contanto que assumam responsabilidade pelas legítimas expectativas geradas pelo seu afeto. Esses sinais seriam: o respeito e a assistência mútuos, a publicidade, a estabilidade a durabilidade, dentre outros. Observe-se ainda que, em nenhum momento, nesse novo conceito de família como garantia institucional, impõe-se o dever de monogamia e também que ele não privilegia a forma do casamento.

A discussão sobre a família como garantia institucional não aparece com esses expressos termos nos votos dos outros Ministros, mas a sua argumentação se aproxima do que se vem discutindo, quando afirmam uma visão da família funcionalizada, destinada ao livre desenvolvimento da personalidade dos

42 BRASIL. Supremo Tribunal Federal. Arguição de Descumprimento de Preceito Fundamental. ADPF 132 - RJ. Tribunal Pleno. Arguente: Governo do Estado do Rio de Janeiro. Arguidos: Governador do Estado do Rio de Janeiro, Assembleia Legislativa do Estado do Rio de Janeiro e Tribunais de Justiça dos Estados. Relator: Min. Ayres Britto. Brasília, 05 de maio de 2011. Disponível em: <http:// redir.stf.jus.br/paginadorpub/paginador.jsp?docTP=AC\&docID=628633 $>$. Acesso em: 17 set. 2015 . seus integrantes. No limite, estão a reconhecer que o que caracteriza a "instituição da família", o seu conteúdo material, visto sob a ótica constitucional, são elementos e requisitos tão "abrangentes" e "abstratos" quanto os elencados pelo Ministro Fux.

$\mathrm{Na}$ interpretação do voto do Ministro Fux, podemos visualizar o emprego das garantias institucionais, com base em uma perspectiva evolutiva. Em cada momento histórico, e em cada paradigma de interpretação constitucional, os institutos assumiriam um conteúdo, que lhes foi historicamente legado e que, portanto, não representaria uma inovação do arbítrio jurisprudencial, mas que, ao mesmo tempo, deveria resultar na melhor compatibilização das liberdades individuais com os imperativos da segurança jurídica. Seria o equilíbrio atualizado e atualizável entre a forma do direito e a luta incessante de afirmação identitária individual e das liberdades construídas coletivamente na coexistência em sociedade. $\mathrm{Na}$ síntese de Márcio Iório, do que foi colocado até agora:

[...] as garantias institucionais comportam, ainda, uma dupla função, por um lado, atualizadora e materializadora de conteúdo, em virtude da bagagem teórica de que foi fruto, e por outro lado, uma função protetora da essência dos direitos fundamentais, como decorrência lógica de sua assimilação de conteúdo jurídico. O institucional é equilíbrio e interação, e, por isso, as garantias institucionais não podem ser simplesmente, como também não podem deixar de ser proteção às formas instituídas. Para preservarem o instituído, têm de dosar sua manutenção e sua transformação de forma ponderada. ${ }^{43}$

\section{Para uma família sem dogmas ou a teoria das garantias institucionais vale a pena?}

Apesar de sua potencial utilidade, para a ampliação das formas de vida afetiva reconhecidas pelo Direito (assim como serviu, a seu tempo, para restringi-las), a teoria das garantias institucionais, mesmo em sua renovada e reconstruída manifestação, pode não conseguir se libertar da carga autoritária e homogeneizante de seu sentido originário. Mesmo a nova teoria constitucional das garantias institucionais precisa pressupor que um conteúdo objetivo pode estar

ARANHA, M. I. Interpretação constitucional e as garantias institucionais dos direitos fundamentais. 2. ed. São Paulo: Atlas, 2000. p. 199. 
contido em formas jurídicas, impregnando-as e condicionando a sua aplicação. Ainda que admita que esse conteúdo mude, que o sentido objetivo do direito se altere, incorporando novos sentidos, com o passar do tempo, e com a complexificação social, essa concepção, mesmo que só por um determinado período, pressupõe a existência de conteúdo fixo, determinável e único de um dado instituto e, por consequência, dos direitos que ele conformaria.

Nesse ponto, reside o perigo da homogeneização, do retorno a uma ética monista, da instrumentalização das garantias institucionais por uma maioria tradicionalmente privilegiada que assumisse os valores propalados por sua forma de vida abrangente como a melhor representação contextualizada do sentido objetivo do Direito e, com isso, pretendesse não mais inviabilizar a mudança social, garantindo a imutabilidade de sua precedência na hierarquia da ordem de valores imposta pelo direito, mas dificultá-la e direcioná-la.

$\mathrm{O}$ respeito pela segurança jurídica não impõe controle da mudança. Essa é uma pretensão autoritária. A alteração da sociedade é incontrolável e a subversão das ordens valorativas, inevitável. Caso a teoria das garantias institucionais pretenda projetar a evolução da sociedade, por meio da redução da velocidade da mudança valorativa e de seu direcionamento, estará fadada ao fracasso. O máximo que a forma do Direito pode exigir é o respeito aos direitos individuais, mas nunca a manutenção de valores sociais, até porque estes, em uma sociedade hipercomplexa, são tantos quantos são as formas de vida abrangentes que convivem em situação de igualdade perante o Estado.

A assimetria do tratamento legal conferido a cada um dos relacionamentos afetivos simultâneos, o legitimado pela forma do casamento e o espúrio, paralelo à família oficial, que usualmente se justifica pela proteção da família como instituto, na realidade tem, como objetivo último, a proteção do patrimônio familiar, entendido este no sentido material e simbólico. Vantagens econômicas e susceptibilidades de um núcleo familiar se sobrepõem ao próprio reconhecimento da dignidade do outro, como locus de realização afetiva.

A preocupação com a defesa econômica e ética da família oficial, aquela que optou pelo caminho formalmente fixado para a sua constituição, funciona como "dogma naturalizado a ponto de se tornar incontestável, possível alternativa". Ao fim e ao cabo, "norma ditada em prol das conveniências e interesses" de uma maioria portadora de uma ética que procura impor por meio dos mecanismos de controle social, inclusive o Direito, e reproduzida pelos operadores dessa ordem, os juristas. ${ }^{44}$

A saída desse "delírio declamatório" dos "mores da estrutura estabelecida" só será possível com a "devolução das normas ao seu posto real e em perpétuo devenir, na práxis sociopolítica." ${ }^{45}$ Aos cidadãos, destinatários e produtores das normas, deve caber a organização livre e responsável de suas relações de afeto, sem que o Judiciário, agindo como último bastião de uma moralidade em decomposição, decida qual é a vida familiar que tem mais valor.

A ampla liberdade de estruturação do afeto não pode significar, entretanto, irresponsabilidade. Dos indivíduos se deve exigir total responsabilidade pelas uniões afetivas constituídas. O preço da autonomia para produzir os padrões da organização familiar é a responsabilidade integral pelos companheiros em comunhão de vida.

À união simultânea ao matrimônio ou a outra(s) união(ões) de fato que seja ostensiva, estável e fundada no afeto, não se pode deixar de reconhecer o status de família, com todos os efeitos decorrentes de uma união estável. Quanto aos casos de uniões poliafetivas (poliamorismo/único núcleo), que não constituem o foco deste trabalho, é fácil perceber-se que não se enquadrariam simplesmente ao modelo da união estável, ato-fato jurídico. Ainda há bastante espaço para experimentação de regimes jurídicos para essas entidades, as quais se deve estender o status de família, pelos mesmos fundamentos do reconhecimento judicial de uniões de fato paralelas (núcleos distintos). Deve-se dar ampla liberdade para que os conviventes elejam o modelo de organização de suas relações de afeto e patrimoniais, com a consciência de que o preço da liberdade é a vedação ao descompromisso.

\section{Referências}

ARANHA, M. I. Interpretação constitucional e as garantias institucionais dos direitos fundamentais. São Paulo: Atlas, 1999.

44 LYRA FILHO, Roberto. Para um direito sem dogmas. Porto Alegre: Fabris, 1980. p. 12.

45 LYRA FILHO, Roberto. Para um direito sem dogmas. Porto Alegre: Fabris, 1980. p. 12. 
ARANHA, M. I. Interpretação constitucional e as garantias institucionais dos direitos fundamentais. 2. ed. São Paulo: Atlas, 2000.

BÖCKENFÖRDE, Ernst Wolfgang. Escritos sobre derechos fundamentales. Baden-Baden: Nomos Verlagsgesellschaft, 1993.

BONAVIDES, Paulo. Curso de direito constitucional. 25. ed. São Paulo: Malheiros, 2010.

BRANCO, Paulo Gustavo Gonet; COELHO, Inocêncio Mártires; MENDES, Gilmar Ferreira. Curso de direito constitucional. 4. ed. rev. e atual. São Paulo: Saraiva, 2009.

BRASIL. Supremo Tribunal Federal. Arguição de Descumprimento de Preceito Fundamental. ADPF 132 - RJ. Tribunal Pleno. Arguente: Governo do Estado do Rio de Janeiro. Arguidos: Governador do Estado do Rio de Janeiro, Assembleia Legislativa do Estado do Rio de Janeiro e Tribunais de Justiça dos Estados. Relator: Min. Ayres Britto. Brasília, 05 de maio de 2011. Disponível em: $<$ http://redir.stf.jus.br/paginadorpub/paginador.jsp?doc$\mathrm{TP}=\mathrm{AC} \& \operatorname{doc} \mathrm{ID}=628633>$. Acesso em: 17 set. 2015.

BRASIL. Supremo Tribunal Federal. Recurso Especial. Resp. n. 183.718 - SP. Quarta Turma. Recorrente: Alice Ferreira dos Santos. Recorrido: Armando Cesar Soeiro. Relator: Min. Sálvio de Figueiredo Teixeira. Brasília, 13 de outubro de 1998. Disponível em: <http://stj.jusbrasil. com.br/jurisprudencia/456377/recurso-especial-resp-183718-sp-1998-0055882-9>. Acesso em: 17 set. 2015.

BRASIL. Supremo Tribunal Federal. Recurso Extraordinário. RE 397762 BA. Primeira Turma. Recorrente: Estado da Bahia. Recorrido: Joana da Paixão Luz. Relator: Min. Marco Aurélio. Brasília, 03 de junho de 2008. Disponível em: <http://stf.jusbrasil.com.br/jurisprudencia/2918741/ recurso-extraordinario-re-397762-ba $>$. Acesso em: 17 set. 2015 .

CANOTILHO, J. J. Gomes. Direito constitucional e teoria da constituição. 5. ed. Coimbra: Almedina, 1991.

ENGELS, Friedrich. A origem da família, da propriedade privada e do Estado. 2. ed. rev. São Paulo: Escala, 2008.

FERRAZ, Paula Carvalho. O concubinato e uma perspectiva de inclusão constitucional. Disponível em: <http:// www.ibdfam.org.br/artigos>. Acesso em: 09 abr. 2012.
GONÇALVES, Carlos Roberto. Direito civil brasileiro. 6. ed. São Paulo: Saraiva, 2009. v. 6.

GONÇALVES, Carlos Roberto. Direito civil brasileiro. 8. ed. São Paulo: Saraiva, 2011. v. 6.

HABERMAS, Jürgen. A inclusão do outro: estudos de teoria política. São Paulo: Loyola, 2002.

LÔBO, Paulo Luís Neto. Famílias. São Paulo: Saraiva, 2010.

LYRA FILHO, Roberto. O que é direito. São Paulo: Brasiliense, 2007.

LYRA FILHO, Roberto. Para um direito sem dogmas. Porto Alegre: Fabris, 1980.

MARTÍNEZ-PUJALTE, Antonio-Luis. La garantía del contenido esencial de los derechos fundamentales. Madrid: Centro de Estudios Constitucionales, 1997.

OLIVEIRA, Euclides Benedito de. União estável: do concubinato ao casamento. 6. ed. São Paulo: Método, 2003.

PIEROTH, Bodo; SCHLINK, Bernhard. Direitos fundamentais: direito estadual II. São Paulo: Saraiva, 2011.

RODRÍGUEZ-ARMAS, Magdalena Lorenzo. Análisis del contenido esencial de los derechos fundamentales enunciados en el art. 53.1 de la Constitución Española. Granada: Comares, 1996.

RUZYK, Carlos Eduardo Pianovski. Famílias Simultâneas e Monogamia. In: CONGRESSO BRASILEIRO DE DIREITO DE FAMÍlLI, 5., 2006, Belo Horizonte. Família e dignidade humana: Anais... São Paulo: IOB Thomson, 2006. p. 193-221.

RUZYK, Carlos Eduardo Pianovski. Famílias simultâneas: da unidade codificada à pluralidade constitucional. Rio de Janeiro: Renovar, 2005.

SANTAMARÍA PASTOR, J. A. Fundamentos de derecho administrativo. Madrid: Centro de Estudios Ramón Areces, 1988. 